\title{
Patient preferences for rheumatoid arthritis treatments: results from the national cross-sectional LERACS study
}

This article was published in the following Dove Press journal:

Patient Preference and Adherence

\author{
Fouad Fayad' \\ Nelly R Ziade' \\ Georges Merheb ${ }^{2}$ \\ Said Attoui ${ }^{3}$ \\ Alla Aiko ${ }^{4}$ \\ Kamel Mroue ${ }^{3}$ \\ Abdel Fattah Masri ${ }^{5}$ \\ 'Rheumatology Department, Hotel \\ Dieu de France Hospital, Saint \\ Joseph University, Beirut, Lebanon; \\ ${ }^{2}$ Department of Rheumatology, \\ Notre Dame des Secours University \\ Hospital, Jbeil, Lebanon, Holy \\ Spirit University, Kaslik, Lebanon; \\ ${ }^{3}$ Rheumatology Department, \\ Hammoud University Medical Center, \\ Saida, Lebanon; ${ }^{4}$ Department of \\ Medicine (Rheumatology), Saint \\ George Hospital, Beirut, Lebanon; \\ ${ }^{5}$ Department of Internal Medicine \\ (Rheumatology), American University \\ of Beirut Medical Center, Beirut, \\ Lebanon
}

Introduction: To investigate the treatment preferences of patients with rheumatoid arthritis (RA) and determine whether these preferences are related to specific disease characteristics.

Method: A national survey was designed to collect demographic, disease, treatment, and preference data on RA patients enrolled in 7 private and university hospital clinics in Lebanon. Associations between patient factors and treatment preferences for RA were analyzed by $\chi^{2}$ or Mann-Whitney $U$ test.

Results: A total of 693 patients ( $83 \%$ female; $67 \%$ aged $41-70$ years) consulting 7 trained rheumatologists completed the survey. Most patients ( $80 \%)$ had established RA $>24$ months, and approximately one-third (34\%) were in remission according to the disease activity score in 28 joints (DAS28). Most (87\%) were receiving oral agents (60\% oral only). Almost twothirds of patients (64\%) expressed a preference for oral treatments, and more than half (53\%) ranked doctor's advice as the most influential factor when choosing treatment. In univariable analysis, health coverage, radiographic damage, disease duration, current therapy, and previous side effects were significantly associated with treatment preference. In multivariable analyses, only radiographic damage and current route of administration were independently associated with preference (both $P<0.001$ ), with patients with no radiographic damage and those on oral-only therapy being more likely to prefer oral agents.

Conclusion: RA patients expressed a preference for oral rather than subcutaneous/intravenousadministered drugs. Understanding patients' preferences may help to inform policymaker decisions.

Keywords: rheumatoid arthritis, administration, patient, preference

\section{Introduction}

Despite the wide range of available treatments, rheumatoid arthritis (RA) continues to pose a substantial burden across the globe, with unmet needs in key domains such as pain, physical and mental functions, and fatigue. Although achievable outcomes for RA continue to evolve and improve, treatment goals and expectations are seldom fully met for patients and physicians alike. ${ }^{1}$ In 2012, Slim and Uthman ${ }^{2}$ reported that "treatment of rheumatic conditions in the Middle East and North Africa (MENA) region is still poorly addressed, inadequately funded and insufficiently reported in the national statistics of the MENA region, and Lebanon is no exception." A 2007 population-based survey conducted in 3,530 individuals aged over 15 years found a high burden of rheumatic diseases in Lebanon, with prevalence rate of RA being the most common at $1.0 \% .^{3}$ This high prevalence of rheumatic diseases merits urgent attention from national health care policymakers.
Correspondence: Fouad Fayad Rheumatology Department, Hotel Dieu de France Hospital, Saint Joseph University, Alfred Naccache Street, Achrafieh, PO Box 166830, Beirut, Lebanon

Tel/fax +96I I 616688

Email fouadfayad@yahoo.fr 
The prevalence of RA in the MENA region seems in the same range as in developed and industrialized countries. ${ }^{4}$ However, patients in developing nations, on average, are relatively more disabled than their counterparts in industrialized nations possibly due to lack of social resources and state support. ${ }^{5}$ Treatment strategy in RA aims to achieve remission or low disease activity as early as possible. Hence knowledge gaps in the extent and severity of RA in MENA countries could result in delays between symptom onset, referral, diagnosis, and the introduction of disease-modifying antirheumatic drugs (DMARDs), as well as low use of DMARDs and intensive therapy. ${ }^{4}$

It is well known and conceptually implicit that patients will prefer to receive an oral drug over subcutaneous (SC) or intravenous (IV) injections/infusions. On the other hand, it is believed that adherence to treatment is lower with oral drugs than those given via SC/IV route. Understanding patient preferences over what treatments they wish to receive would help inform physicians and health authorities to make decisions in selecting and providing treatments that patients are likely to accept. ${ }^{6}$ Therefore, we aimed through a national survey to assess RA patients' preferences for the route of administration of DMARDs, and to identify the preferences determining factors.

\section{Materials and methods}

The LERACS (LEbanese Rheumatoid Arthritis Cohort Survey) study is a multicenter, cross-sectional patient survey that was designed to collect data on RA patients from private clinics and university hospitals. The 7 rheumatologists who participated in the study were practicing in various regions in Lebanon (central Beirut and other districts) and different settings (university teaching hospitals and private clinics); hence, it is believed that the data are fairly representative of the overall RA population in Lebanon.

The survey questionnaire was drafted by 2 rheumatologists (FF,NZ) based on a literature search, then presented and discussed with the group of participating rheumatologists for comments and final approval during a 4-hour meeting. The panel did not request patient input into the development of the questionnaire.

The questionnaire comprised 5 parts: demographics, disease characteristics, comorbidities, treatment preference, and reason for preference (Supplementary material). The study was approved by the Ethical Committee of Hotel Dieu de France Hospital, affiliated to Saint Joseph University, Beirut/Lebanon. All patients gave written informed consent for this study.

Questionnaires were administered during medical consultations in the format of an interview between doctor and patient. Consecutive patients over a fixed 3-month period were asked about their use of RA treatments; their preferences for oral (no targeted synthetic DMARDs were available in Lebanon at the time the survey was undertaken), IV, or SC route; and the role of their physician in treatment decision-making. Data on patient demographics and disease characteristics were extracted from the medical records.

Results for categorical variables were summarized as means and percentages. For numerical variables, results were summarized using means and standard deviations or, in the case of variables with particularly skewed distributions, medians and interquartile ranges. Predetermined analyses, based on addressing questions of clinical importance, examined associations between variables using the $\chi^{2}$ test or Mann-Whitney $U$ test. Where necessary, categories containing very few responses were combined with a similar category for the purposes of analysis. Univariable then multivariable analysis was used to assess variables that were significantly associated with treatment preferences. A $P$-value $<0.05$ was regarded as statistically significant.

\section{Results}

\section{Patient and disease characteristics}

Consecutive patients over a fixed 3-month period were invited to participate and a total of 693 patients completed the survey; all patients who were approached accepted the invitation to participate. Table 1 shows the patient demographics; most (83\%) were female, $67 \%$ were aged between 41 and 70 years, $55 \%$ were unemployed, and only

Table I Demographic characteristics of patients $(n=693)$

\begin{tabular}{ll}
\hline Variable & \% of patients \\
\hline Age (years) & \\
$\leq 30$ & 7.2 \\
$3 I-40$ & 10.2 \\
$4 I-50$ & 20.2 \\
$5 I-60$ & 28.7 \\
$6 I-70$ & 20.3 \\
$7 I-80$ & 10.8 \\
$\geq 8 I$ & 2.7 \\
Female & 83.0 \\
Current smoker & 34.6 \\
Arab ethnicity & 99.0 \\
Employment status & \\
Full-time employed & 27.6 \\
Part-time employed & 6.1 \\
Self-employed & 9.2 \\
Student & 1.4 \\
Retired & 0.8 \\
Unemployed & $\mathbf{5 5}$ \\
\hline
\end{tabular}

Notes: $\mathrm{n}=693$ is the pooled total, with some responses missing in some categories. The bold values indicate the highest percentage among all age groups and employment status. 
Table 2 Disease and treatment characteristics ( $\mathrm{n}=693$ patients)

\begin{tabular}{|c|c|}
\hline Variable & $\%$ of patients \\
\hline \multicolumn{2}{|l|}{ Disease stage } \\
\hline Very early (<3 months) & 3.1 \\
\hline Early (3-24 months) & 17.3 \\
\hline Established (>24 months) & 79.6 \\
\hline \multicolumn{2}{|c|}{ Disease activity score in 28 joints } \\
\hline Remission $(\leq 2.6)$ & 34.2 \\
\hline Low (2.7-3.2) & 23.2 \\
\hline Moderate (3.3-5.I) & 32.9 \\
\hline High $(>5.1)$ & 9.7 \\
\hline \multicolumn{2}{|l|}{ Radiographic damage } \\
\hline Yes & 44.6 \\
\hline No & 55.4 \\
\hline \multicolumn{2}{|c|}{ Length of symptoms (since onset) } \\
\hline$<5$ years & 39.0 \\
\hline $5-9$ years & 25.0 \\
\hline $10-19$ years & 26.0 \\
\hline$\geq 20$ years & 10.1 \\
\hline \multicolumn{2}{|l|}{ Current medication ${ }^{\mathrm{a}}$} \\
\hline Oral DMARD & 87.0 \\
\hline TNF inhibitor & 25.0 \\
\hline Other biologic & 15.7 \\
\hline \multicolumn{2}{|c|}{ Route of DMARD administration } \\
\hline Intravenous & 4.6 \\
\hline Oral & 59.2 \\
\hline Subcutaneous & 9.3 \\
\hline Oral + intravenous & 13.4 \\
\hline Oral + subcutaneous & 13.4 \\
\hline \multicolumn{2}{|l|}{ Patient preference } \\
\hline IV & 6.2 \\
\hline Oral & 63.6 \\
\hline SC & 8.3 \\
\hline No preference & 21.9 \\
\hline
\end{tabular}

Notes: $n=693$ is the pooled total, with some responses missing in some categories. The bold values indicate the highest percentage among each category.

Abbreviations: DMARD, disease-modifying antirheumatic drug; TNF, tumor necrosis factor; IV, intravenous; SC, subcutaneous.

$12 \%$ had no health coverage. More than one-third (35\%) of patients were smokers. Table 2 shows the patients' disease and treatment characteristics. A large proportion (80\%) of patients had established RA ( $>24$ months); only 3\% had very early disease ( $<3$ months). One-third (34\%) of patients were in remission according to the disease activity score in 28 joints (DAS28). The median duration of symptoms was 6 (interquartile range, $3-13$ ) years.

\section{Current and previous experience with treatment}

A large majority (87\%) of patients were receiving treatment with oral DMARDs (Table 2); $60 \%$ received DMARDs by the oral route alone, and $27 \%$ used oral drugs in combination with IV or SC injections/infusions. Moreover, $43 \%$ $(n=295)$ of patients took corticosteroids, 27\% $(n=184)$ nonsteroidal anti-inflammatory drugs, and $19 \%(n=130)$ other analgesics. In addition, $27 \%(\mathrm{n}=185)$ of patients received antihypertensive drugs, 27\% ( $\mathrm{n}=183)$ antiosteoporosis agents, $19 \%(\mathrm{n}=133)$ lipid-lowering drugs, and $11 \%(\mathrm{n}=75)$ antidiabetic drugs; $43 \%(\mathrm{n}=296)$ were on other comedication. A large proportion $(84 \% ; n=584)$ of patients had previously taken oral DMARDs, and 15\% (n=104) tumor necrosis factor (TNF) inhibitors. Gastrointestinal intolerance was the most common drug side effect reported $(18 \% ; n=121)$, followed by liver toxicity $(5 \% ; n=36)$, hair loss $(4 \% ; n=29)$, and allergy $(4 \% ; n=27)$.

\section{Patient preferences and their associations}

The survey revealed that $64 \%$ of patients preferred oral over other routes of medication. A smaller number preferred IV or SC administration, while nearly one-quarter (22\%) had no preference (Table 2). More than half $(53 \% ; n=355)$ of the patients ranked doctor's advice as the most important influencing factor when choosing treatment, followed by the drug efficacy $(27 \% ; n=178)$, risk of side effects $(10 \%$; $n=65)$, fear of injection $(5 \% ; n=32)$, insurance coverage $(3 \% ; n=23)$, and price $(2 \% ; n=15)$.

In univariable analyses of associations between various patient factors and expressing preference for oral route of administration, significant associations were found for health coverage $(P<0.001)$, radiographic damage $(P<0.001)$, disease duration $(P=0.005)$, current therapy route $(P<0.001)$, and previous side effects $(P=0.002)$ (Table 3$)$. Sex, age, smoking status, education, disease activity score, and number of medications were not significantly associated with patients' preference.

In multivariable analysis, only radiographic damage and current route of administration were independently associated with preference for oral therapy (both $P<0.001$ ). Odds ratios were 0.27 (95\% CI 0.15-0.49) for radiographic damage (vs no damage) and 8.97 (95\% CI 4.35-18.5) for current oral route (vs current IV + IV/oral and SC + SC/oral) (Table 4). Thus, those taking oral-only therapy were almost 9 times more likely than those on IV or IV/oral therapy to prefer oral administration.

Patients with radiographic damage were approximately 4 times less likely than those with no damage to prefer oral therapy.

\section{Discussion}

This was the first study that analyzed treatment preferences in a large sample of RA patients in the MENA region. Patients in this region are managed following the same treatment strategies as those followed across Europe, most commonly the EULAR Guidelines. Most respondents to this survey of 
Table 3 Univariable analysis of factors associated with patient preference administration route

\begin{tabular}{|c|c|c|c|}
\hline Variable & $\begin{array}{l}\text { Number (\%) } \\
\text { preferred oral }\end{array}$ & $\begin{array}{l}\text { Odds ratio } \\
(95 \% \mathrm{Cl})\end{array}$ & $P$-value \\
\hline Age (years) & & & 0.67 \\
\hline$\leq 30$ & 29/33 (87.9) & 1 & \\
\hline $31-40$ & $39 / 53(73.6)$ & $0.38(0.11-1.29)$ & \\
\hline $4 I-50$ & $83 / 101$ (82.2) & $0.64(0.20-2.03)$ & \\
\hline $5 I-60$ & $126 / 154(81.8)$ & $0.62(0.20-1.91)$ & \\
\hline $6 I-70$ & $85 / 106(80.2)$ & $0.56(0.18-1.76)$ & \\
\hline$\geq 71$ & $62 / 75$ (82.7\%) & $0.66(0.20-2.19)$ & \\
\hline Sex & & & 0.80 \\
\hline Female & $358 / 44 \mid(8 I .2)$ & I & \\
\hline Male & $70 / 85(82.4)$ & $1.08(0.59-1.98)$ & \\
\hline Smoker & & & 0.33 \\
\hline No & 267/334 (79.9) & 1 & \\
\hline Yes & 156/187 (83.4) & $1.26(0.79-2.02)$ & \\
\hline Education & & & 0.56 \\
\hline None & $102 / 128$ (79.7) & I & \\
\hline High school & 193/239 (80.8) & I.07 (0.62-I.83) & \\
\hline Undergraduate & $70 / 86(81.4)$ & $1.12(0.56-2.23)$ & \\
\hline Postgraduate & $56 / 64(87.5)$ & $1.78(0.76-4.20)$ & \\
\hline Health coverage & & & $<0.001$ \\
\hline None & $65 / 68(95.6)$ & 1 & \\
\hline Partial & I79/220 (8I.4) & $0.20(0.06-0.67)$ & \\
\hline Full & I78/230 (77.4) & $0.16(0.05-0.52)$ & \\
\hline DAS category & & & 0.84 \\
\hline Remission & |4|/| 62 (87.0) & $\mathrm{I}$ & \\
\hline Low & $97 / 114$ (85.I) & $0.85(0.43-1.69)$ & \\
\hline Moderate & $120 / 144(83.3)$ & $0.74(0.39-1.40)$ & \\
\hline High & $258 / 33(84.9)$ & $0.83(0.29-2.40)$ & \\
\hline Radiographic damage & & & $<0.001$ \\
\hline No & 238/259 (91.9) & 1 & \\
\hline Yes & $143 / 196(73.0)$ & $0.24(0.14-0.4 I)$ & \\
\hline Current route & & & $<0.001$ \\
\hline IV + IV/oral & $44 / 77(57.1)$ & I & \\
\hline $\mathrm{SC}+\mathrm{SC} / \mathrm{oral}$ & $53 / 97(54.6)$ & $0.90(0.49-1.65)$ & \\
\hline Oral & $315 / 336(93.8)$ & II.3 (5.98-21.2) & \\
\hline Number of pills/d & & & 0.41 \\
\hline 0 & $54 / 67(80.6)$ & 1 & \\
\hline $1-3$ & I 78/226 (78.8) & $0.89(0.45-1.77)$ & \\
\hline $4-9$ & $160 / 192(83.3)$ & $1.20(0.59-2.46)$ & \\
\hline$\geq 10$ & $37 / 42(88.1)$ & $1.78(0.59-5.42)$ & \\
\hline Previous side effect & & & 0.002 \\
\hline No & $324 / 383(84.6)$ & 1 & \\
\hline Yes & $105 / 144(72.9)$ & $0.49(0.31-0.78)$ & \\
\hline
\end{tabular}

Note: Bold P-values indicate statistically significant.

Abbreviations: IV, intravenous; SC, subcutaneous.

Table 4 Multivariable analysis of factors associated with patient preference administration route

\begin{tabular}{llll}
\hline Variable & Category & Odds ratio (95\% CI) & P-value \\
\hline Radiographic damage & No & I & $<0.00 \mathrm{I}$ \\
& Yes & $\mathbf{0 . 2 7}(\mathbf{0 . 1 5 - 0 . 4 9 )}$ & \\
Current route & $\mathrm{IV}+\mathrm{IV} /$ oral & $\mathrm{I}$ & $<0.00 \mathrm{I}$ \\
& $\mathrm{SC}+\mathrm{SC} /$ oral & $\mathrm{I} .03(0.53-2.08)$ & \\
& Oral & $\mathbf{8 . 9 7}(\mathbf{4 . 3 5}-1 \mathbf{8 . 5})$ & \\
\hline
\end{tabular}

Note: Bold values indicate modal values.

Abbreviations: IV, intravenous; SC, subcutaneous.
Lebanese RA patients expressed a preference for oral therapy. Preference for the oral route was significantly associated with lack of health coverage or radiographic damage, shorter disease duration, current oral therapy route, and no prior history of side effects. Independent associations with preference were found for radiographic damage and current oral route. The patients' treatment choices were influenced mainly by physician advice, followed by experience with current or previous treatments. The questionnaire used in this study was developed and validated only by rheumatologists with no patient input, which may be regarded as a minor limitation of this research.

Research from Europe demonstrates the importance of informing patients about RA and its treatment. ${ }^{7,8}$ In Norway, for example, high patient involvement in medical decisionmaking was associated with greater satisfaction with treatment received and better health status. ${ }^{8}$ Meanwhile, a Portuguese questionnaire study conducted in 223 RA patients found that as many as $68 \%$ reported that their rheumatologist was their preferred source of information about the disease and its treatment. ${ }^{9}$ Similar trends were observed in the present study: our surveyed patients were significantly more likely to prefer their current over alternative modes of treatment, and over half indicated that physician advice was the most influential factor when making decisions over treatment.

In 380 commercially insured RA patients surveyed in the US, route of administration was the most important attribute of RA treatment, followed by frequency of administration. ${ }^{6}$ Just over half $(56 \%)$ the patients preferred oral route of administration over parenteral routes. In another US survey of 250 RA patients who had discontinued anti-TNF therapy, $41 \%$ cited injection experience (pain/burning/discomfort during or after injection, redness/swelling after injection, dislike of self-injection or of injection frequency, fear of needles) as an important reason for discontinuation. ${ }^{10}$ A German discrete-choice experiment performed in 1,588 RA patients found that "oral administration" and "no combination with methotrexate" were the most highly desired characteristics of a second-line DMARD, with "intravenous infusion" being among the most strongly rejected. ${ }^{11}$ The authors concluded that an oral DMARD excluding methotrexate is a highly favorable treatment option that may increase compliance and adherence in RA treatment.

The present large-scale survey conducted in nearly 700 patients with RA similarly confirmed a strong preference for oral rather than SC/IV administration of drugs in those who were already taking oral agents, whereas the proportions of patients taking parenterally administered drugs were similar to the rates of expressing a preference for these routes of administration, suggesting that patient satisfaction 
that SC/IV drugs, which are usually prescribed for more advanced disease, could improve their condition overrode their reluctance to receive injections/infusions. These findings were also echoed in our observation that the presence of radiographic damage was significantly associated with an approximately 4 times lower risk of preference for oral drugs; patients with more severe disease seem to want more potent treatments regardless of route of administration. This may be because these patients may prefer to visit a hospital to receive an infusion (perhaps in order to have interactions with health care professionals), have concerns about their ability to adhere to an oral medicine, or believe an injection or infusion is more powerful than an oral alternative, particularly as there are few oral therapies for moderate-to-severe ulcerative colitis currently available. ${ }^{12}$

\section{Conclusion}

Lebanese RA patients expressed a high preference for oral agents, and mostly cited physician advice as the most important influencing factor in their treatment decisions. When making funding decisions, policymakers are encouraged to consider patients' requirements, experiences, goals, and preference, so understanding patients' preferences may help to inform health care policymakers in providing a selection of treatments. ${ }^{13}$

\section{Role of the study sponsor}

Medical writing support under the direction of the authors was provided by Synergy Medical, and funded by Pfizer Inc.

\section{Acknowledgment}

This paper was presented as an oral communication at APLAR on October 2017 and as a poster/abstract at ACR in 2016. http://acrabstracts.org/abstract/patient-preferencesregarding-rheumatoid-arthritis-therapies-in-lebanon-resultsfrom-a-national-multicenter-cross-sectional-survey/.

\section{Disclosure}

Fouad Fayad received grants and/or research support from NewBridge and Pfizer; consulting fees from AbbVie, Celgene, Janssen, Pfizer, Roche, Novartis, Lilly, NewBridge, and Sanofi-Aventis; speaker's bureaus for AbbVie, Pfizer, Roche, Novartis, Lilly, NewBridge, Bristol-Myers Squibb, Janssen, Algorithme, and Sanofi-Aventis; and other support from AbbVie, Pfizer, Roche, Novartis, Lilly, NewBridge, Celgene, and Sanofi-Aventis.

Nelly R Ziade received grants and/or research support from AbbVie, Celgene/Algorithme; consulting fees from AbbVie, Celgene, Pfizer, Janssen, Lilly, Novartis, Roche, and Sanofi-Aventis; speaker's bureaus for AbbVie, Pfizer, Janssen, Lilly, Novartis, Roche, and Sanofi-Aventis; and other support from AbbVie, Celgene, Pfizer, Janssen, Lilly, Roche, and Sanofi-Aventis.

Georges Merheb received grants and/or research support from Pfizer, AbbVie, Lilly, Roche, Sanofi-Aventis, NewBridge, and Janssen; consulting fees from Pfizer, AbbVie, Lilly, Roche, Sanofi-Aventis, NewBridge, and Janssen; and other support from Pfizer, AbbVie, Lilly, Roche, Sanofi-Aventis, NewBridge, and Janssen.

Said Attoui received consulting fees from Pfizer, AbbVie, Roche, Sanofi-Aventis, and Janssen; speaker's bureaus for Pfizer, AbbVie, Roche, Sanofi-Aventis, and Janssen; and other support from Pfizer, AbbVie, Roche, Sanofi-Aventis, and Janssen.

Alla Aiko received consulting fees from AbbVie, Roche, and Pfizer; speaker's bureaus for AbbVie, Pfizer, Janssen, Lilly, Novartis, Roche, NewBridge and Sanofi-Aventis; and other support from AbbVie, Roche, and Pfizer.

Kamel Mroue received consulting fees from AbbVie, Roche, Pfizer, Jensen, and Eli Lilly; speaker's bureaus for AbbVie, Roche, Pfizer and Jensen, MSD, Eli Lilly, BMS, and Sanofi-Aventis; and other support from AbbVie, Roche, and Pfizer. Abdel Fattah Masri received consulting fees from Pfizer Inc. The authors report no other conflicts of interest in this work.

\section{References}

1. Taylor PC, Moore A, Vasilescu R, Alvir J, Tarallo M. A structured literature review of the burden of illness and unmet needs in patients with rheumatoid arthritis: a current perspective. Rheumatol Int. 2016; 36(5):685-695.

2. Slim ZFN, Uthman I. The state of rheumatic diseases in Lebanon. Rheumatology. 2012;51(11):1929-1930.

3. Chaaya M, Slim ZN, Habib RR, et al. High burden of rheumatic diseases in Lebanon: a COPCORD study. Int J Rheum Dis. 2012;15(2):136-143.

4. El Zorkany B, Alwahshi HA, Hammoudeh M, et al. Suboptimal management of rheumatoid arthritis in the Middle East and Africa: could the EULAR recommendations be the start of a solution? Clin Rheumatol. 2013;32(2):151-159.

5. Kalla AA, Tikly M. Rheumatoid arthritis in the developing world Best Pract Res Clin Rheumatol. 2003;17(5):863-875.

6. Louder AM, Singh A, Saverno K, et al. Patient preferences regarding rheumatoid arthritis therapies: a conjoint analysis. Am Health Drug Benefits. 2016;9(2):84-93.

7. Bergsten U, Bergman S, Fridlund B, Arvidsson B. "Delivering knowledge and advice": healthcare providers' experiences of their interaction with patients' management of rheumatoid arthritis. Int J Qual Stud Health Well-being. 2011;6(4):8473.

8. Kjeken I, Dagfinrud H, Mowinckel P, Uhlig T, Kvien TK, Finset A. Rheumatology care: involvement in medical decisions, received information, satisfaction with care, and unmet health care needs in patients with rheumatoid arthritis and ankylosing spondylitis. Arthritis Rheum. 2006; 55(3):394-401

9. Cunha-Miranda L, Costa L, Ribeiro JS. NEAR study: Needs and Expectations in Rheumatoid ARthritis - do we know our patients needs? Acta Reumatol Port. 2010;35(3):314-323. 
10. Bolge SC, Goren A, Tandon N. Reasons for discontinuation of subcutaneous biologic therapy in the treatment of rheumatoid arthritis: a patient perspective. Patient Prefer Adherence. 2015;9:121-131.

11. Alten R, Krüger K, Rellecke J, et al. Examining patient preferences in the treatment of rheumatoid arthritis using a discrete-choice approach. Patient Prefer Adherence. 2016;10:2217-2228.

12. Marengo MF, Suarez-Almazor ME. Improving treatment adherence in patients with rheumatoid arthritis: what are the options? Int J Clin Rheumtol. 2015;10(5):345-356.
13. NHS England. Involving people in their own health and care: statutory guidance for clinical commissioning groups and NHS England. Leeds, UK: NHS England. Available from: https:/www.england.nhs.uk/wpcontent/uploads/2017/04/ppp-involving-people-health-care-guidance. pdf. Accessed June 01, 2018. 


\section{Supplementary material}

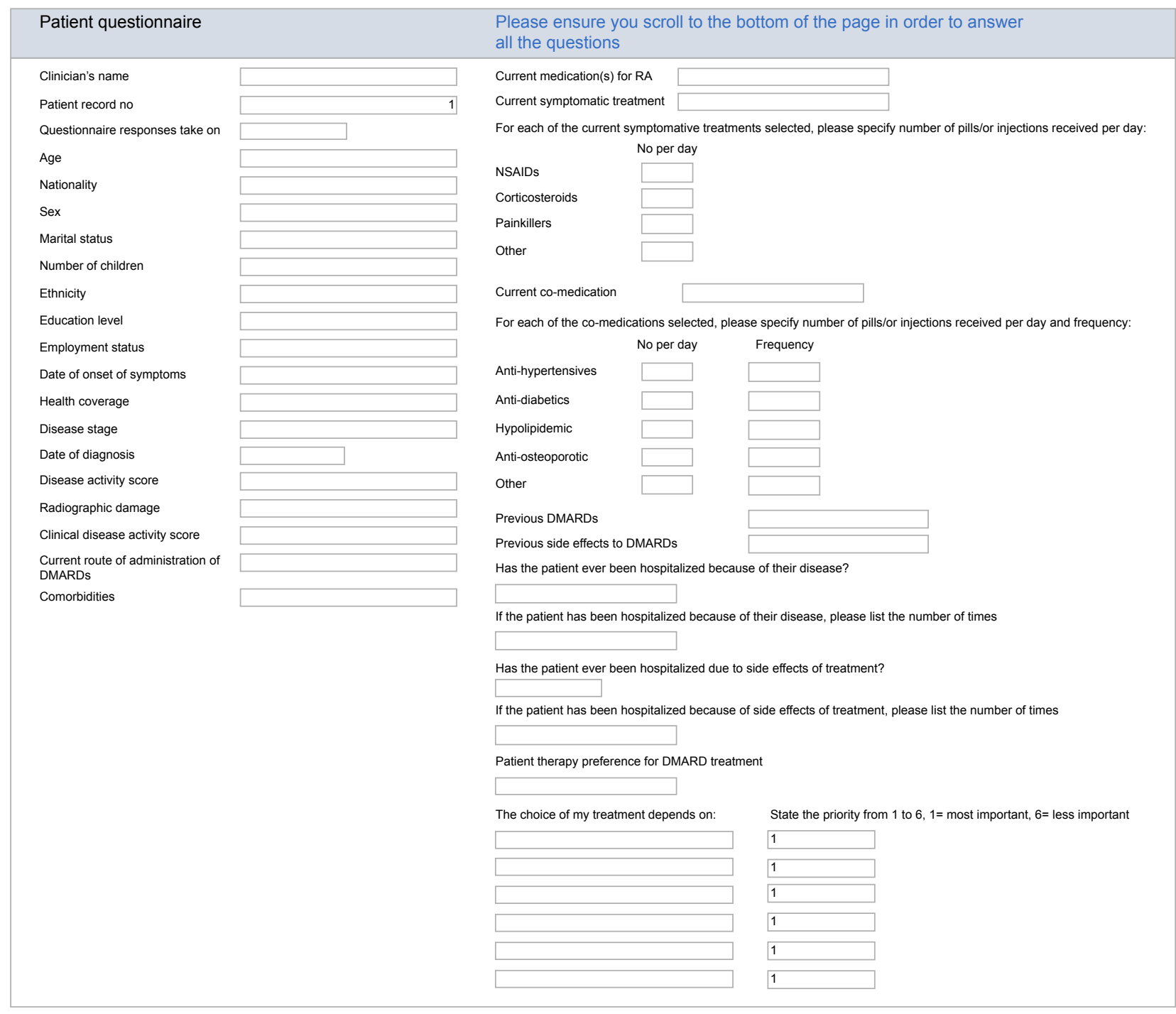

Figure SI Patient questionnaire.

Abbreviations: RA, rheumatoid arthritis; NSAID, nonsteroidal anti-inflammatory drug; DMARD, disease-modifying antirheumatic drug.

Patient Preference and Adherence

Dovepress

\section{Publish your work in this journal}

Patient Preference and Adherence is an international, peer-reviewed, open access journal that focuses on the growing importance of patient preference and adherence throughout the therapeutic continuum. Patient satisfaction, acceptability, quality of life, compliance, persistence and their role in developing new therapeutic modalities and compounds to optimize clinical outcomes for existing disease states are major areas of interest for the journal. This journal has been accepted for indexing on PubMed Central. The manuscript management system is completely online and includes a very quick and fair peer-review system, which is all easy to use. Visit http://www. dovepress.com/testimonials.php to read real quotes from published authors.

\footnotetext{
Submit your manuscript here: http://www.dovepress.com/patient-preference-and-adherence-journal
} 